\title{
Adapting to the Challenges of Chronic Non-communicable Diseases: Evidence from Russia
}

\author{
Christopher J Gerry ${ }^{1,2}$ (D) Maria Kaneva $^{3,4}$ (D)
}

Received: 26 August 2019 / Accepted: 23 March 2020/ Published online: 13 April 2020

(C) The Author(s) 2020

\begin{abstract}
As life expectancies increase and healthcare improves, increasing numbers of the population can expect to live with combinations of two or more chronic noncommunicable diseases (NCDs). Population studies suggest that more than half of older-aged adults report having multiple chronic NCDs (multimorbidities) and twothirds of total health spending in high-income countries is accounted for by patients with multimorbidities. Beyond the need to obviate the growing burden on healthcare systems, the increasing incidence and prevalence of multimorbidity and its effects requires further investigation. Using nationally representative data from a Russian population survey, we examine the impact of chronic NCDs on self-assessed health, explore the prevalence of multimorbidity and, applying an iterative partial proportional odds estimator, examine how different combinations of chronic NCDs interact to influence self-assessed health. Confirming that there are high levels of chronic NCDs and associated multimorbidities, we find that the impact of these on self-assessed health is greater than previous estimates suggested but that, where there are dual morbidities, the effect of the additional disease is weaker than it would have been if experienced as a single condition. We conclude that individuals possess critical adaptive psychological mechanisms which attenuate the incremental health impact of additional chronic NCDs. These are important for understanding the relationship between illness and the quality of life.
\end{abstract}

Keywords Non-communicable disease $\cdot$ Chronic illness $\cdot$ Morbidity $\cdot$ Multimorbidity Self-assessed health $\cdot$ Adaptation $\cdot$ Russia

Christopher J Gerry

christopher.gerry@sant.ox.ac.uk

Maria Kaneva

kaneva@iep.ru

Extended author information available on the last page of the article 


\section{Introduction}

Accounting for two-thirds of global deaths, chronic non-communicable diseases (NCDs) are the leading cause of global mortality and morbidity (United Nations 2011). The simultaneous experience of multiple chronic NCDs is now more prevalent than single condition chronic morbidity (Starfield 2006; Howard et al. 2010). Population studies suggest that over half of elderly adults are experiencing multiple chronic NCDs (Marengoni et al. 2011), and spending on patients with more than one chronic NCD now accounts for around two-thirds of total health spending in high-income countries (Parekh and Barton 2010). In Russia, the focus of this research, over $40 \%$ of the population currently report living with more than one chronic NCD (Kaneva et al. 2018).

Beyond the need to obviate the growing burden on healthcare systems, the increasing incidence and prevalence of multimorbidity poses a set of questions requiring further investigation. ${ }^{1}$ From the diagnostic perspective, multimorbidity complicates disease pathologies, necessitates new approaches to diagnostic classification and presents major challenges in terms of treatment norms and the management of illness. From the patient perspective, more complicated disease management protocol and the anticipation of complex polypharmacy can impact both adherence to medication and healthcare utilisation itself. From the public health perspective, better understanding is needed of the socioeconomic and demographic drivers of multimorbidity (Lorig et al. 2006; Gurthrie et al. 2011), the impacts of different combinations of chronic NCDs and the role that integrated preventive medicine can play in reducing the negative effects of multimorbidity. From the economic perspective, for policy makers to make efficient intervention decisions, it is essential to understand how individuals experience multimorbidity and how it impacts on their quality of life (Hausman 2008).

Across the public health, social epidemiology, psychology, quality of life and health economics literature, there has been a steady growth of interest in studying chronic illnesses and their negative effect on individual well-being in different countries (Fortin et al. 2004; Garin et al. 2016; Kaneva et al. 2018; Mavaddat et al. 2014; McDaid et al. 2013; Momtaz et al. 2010). Besides a strand within this literature which confirms the intuitive idea that experiencing multiple illnesses is worse for individual well-being than having a single illness (Arokiasamy et al. 2015; Kaneva et al. 2018; McDaid et al. 2013; Mavaddat et al. 2014; Momtaz et al. 2010), there is a separate body of literature emerging which investigates whether and how internal mechanisms of adaptation and adjustment may complicate the relationship between objective and subjective quality of life measures at the level of the individual (Salas and Vigorito 2019). Studies of individuals living with chronic NCDs (Cubí-Mollá et al. 2017; Mathew et al. 2012; McTaggard-Cowan et al. 2011), experiencing persistent pain (McNamee and Mendolia 2014) or coping with disability (Antonak and Livneh 1995; Brickman and Coates 1978; Oswald and Powdthavee 2008) suggest that individuals are able to adapt to their circumstances in ways which attenuate the potential cumulative effect of multiple chronic illnesses.

\footnotetext{
${ }^{1}$ In this paper, the term multimorbidity is used rather than comorbidity on the basis that it has a broad and less clinically oriented interpretation, as the simultaneous presence of two or more chronic medical conditions in an individual (Ording and Sorensen 2013).
} 
In the recent economics literature, adaptation has been examined through application of econometric techniques using data on self-assessed health and well-being from individual and household surveys. Oswald and Powdthavee (2008), drawing on life satisfaction data from the British Household Panel Survey, find that individuals experiencing the onset of disability recover between 30 and $50 \%$ of their predisability life satisfaction in subsequent years, when living with the disability. An Australian-based study, by McNamee and Mendolia (2014), argues that, among individuals with chronic pain, it is females that adapt more effectively. Cubí-Mollá et al. (2017), applying a dynamic econometric framework to British Cohort Studies data, find that individuals suffering from a chronic disease are less likely to self-assess their health positively, but that longer durations of living with the chronic disease tend to counter balance this effect over time.

Underpinning these empirical approaches is the idea that a respondent's selfevaluation of their health state may be affected by factors other than their clinical health condition (Cubí-Mollá et al. 2017). For example, a person experiencing a chronic NCD for the first time may calibrate their well-being according to different internal standards compared with somebody with pre-existing conditions or with experience of living with a particular condition. In either case, a form of adaptation or adjustment to the experience of living with chronic NCDs can produce potentially positive changes in how individuals feel about their health and well-being without any notable change in their underlying clinical condition (Ambrosio et al. 2015; Antonak and Livneh 1995; Livneh and Antonak 2005; Moss-Morris 2013; Telford et al. 2006).

The predominant theoretical models that capture these processes of adaptation fall into two main paradigms. The stage theory paradigm, which has been influential in the palliative care setting, posits that individuals adapt by moving through a series of phases, including denial, depression, anger, acknowledgment and adjustment (Antonak and Livneh 1995; Kübler-Ross and Kessler 2014). The second paradigm pivots around the idea that individuals adapt by engaging with a series of adaptive tasks, which are procedurally non-linear and are cognitively unique to the individual (Cohen and Lazarus 1979; Corr et al. 2003; Samson and Siam 2008). Underlying both approaches is an understanding of adaptation as "an intrapsychic process through which past, present, and future situations and circumstances are given such cognitive and emotional meaning that an acceptable level of well-being is achieved. Adaptation in this sense is used for "psychological recuperation after a setback" (Heynik 1993, p. 1332). In the context of multimorbidity, the varieties of chronic illness, and the ways in which they impact on the body and mind, shape the adaptation process, exacerbating challenges where more severe and disabling illnesses are involved (Cubí-Mollá et al. 2017) and raising important but difficult questions concerning how different combinations and quantities of chronic illness relate to the adaptation process.

Using the Russian data, the objective of this study is to contribute to the public health, quality of life and health outcome literature on multimorbidity and health care reform. We explore whether incremental morbidities are experienced synergistically or whether there appear to be mechanisms which attenuate the impact on the individual of an additional NCD. We explain how and why this is significant for policy makers and medical practitioners concerned with enhancing qualify of life within their populations of interest. 


\section{Data and Methods}

This research uses data from Phase II of the Russia Longitudinal Monitoring SurveyHigher School of Economics household survey (hereafter RLMS), yielding a nationally representative population sample from a repeated cross-section survey undertaken each autumn since 1994 (other than in 1997 and 1999). ${ }^{2}$ The survey is based on the principle of 'repeated sampling of dwellings', in which all household members are interviewed each year (if they can be contacted within three visits), and then the dwelling itself (rather than the household) is followed. The survey collects data across a rich range of socioeconomic, demographic and health characteristics of the population. We draw on data from 2013 to 2016 inclusive, providing a total sample, with full information for the core baseline variables and no chronic NCDs of 24,798 . This sample, which we refer to as the 'healthy baseline population', is increased by up to 1750 observations as we add respondents reporting different chronic NCDs.

The dependent variable is derived from a standard survey instrument: 'Tell me, please: how would you evaluate your health?' (very good, good, average, bad or very bad). From this, we create a three-level health state variable (SAH) by merging the categories 'very good' and 'good' into a category 'good health' ( $67.8 \%$ in the 'healthy' baseline regression), 'bad' and 'very bad' into a category 'bad health' ( $0.6 \%$ in the 'healthy' baseline regression), with the remainder classified as 'average health' ( $31.7 \%$ in the baseline regression). The main independent variables of interest are those pertaining to 17 self-reported chronic $\mathrm{NCDs},{ }^{3}$ the prevalence of which is illustrated in Fig. 1.

Chronic NCDs are common among the Russian population but consistent with what we know about the greater engagement that females have with healthcare systems; for all 17 diseases, the reported prevalence is higher among females. For both males and females, the most commonly reported NCD is hypertensive heart disease (high blood pressure), with almost one-third of women and one-fifth of men reporting high blood pressure. The other NCDs, among the top five, are joint disease, gastrointestinal disease, spinal problems and heart disease, with prevalence rates ranging between 15 and $25 \%$ for women, compared with $9 \%$ and $14 \%$ for men. Given that cardiovascular disease is the leading cause of male mortality in Russia (Kaneva et al. 2018), it is likely that the (relatively low) reported prevalence rates for high blood pressure and heart disease reflect the failure of males to present to the healthcare system and thus to have learned about their conditions.

Following the previous literature (e.g. Garin et al. 2016), we identify complex associative multimorbidities in our data, and to capture the scale and range of (dual) multimorbidities, we present them in tabular form in Appendix Figure 2, in which the size of the shaded circle mirrors the prevalence of the respective dual morbidity. ${ }^{4}$ There

\footnotetext{
${ }^{2}$ The RLMS is conducted by the National Research University 'Higher School of Economics' and ZAO 'Demoscope' together with Carolina Population Center, University of North Carolina at Chapel Hill and the Institute of Sociology RAS, www.cpc.unc.edu/projects/rlms-hse and www.hse.ru/org/hse/rlms.

${ }^{3}$ Heart disease, lung disease, liver disease, kidney disease, gastrointestinal disease, spinal conditions, endocrine disease and diabetes, hyperintensive heart/blood pressure, joint disease, disease of the upper respiratory tract, neurological disease, eye disease, allergies, varicose veins, skin disease, oncological disease, urogenital system disease.

${ }^{4}$ An 'associative multimorbidity' refers to diseases with a statistical association not known to be causal or not known to share common pathogenic mechanisms or origins (Starfield 2006).
} 
NCD prevalence in males and females

(RLMS, 2013-2016)

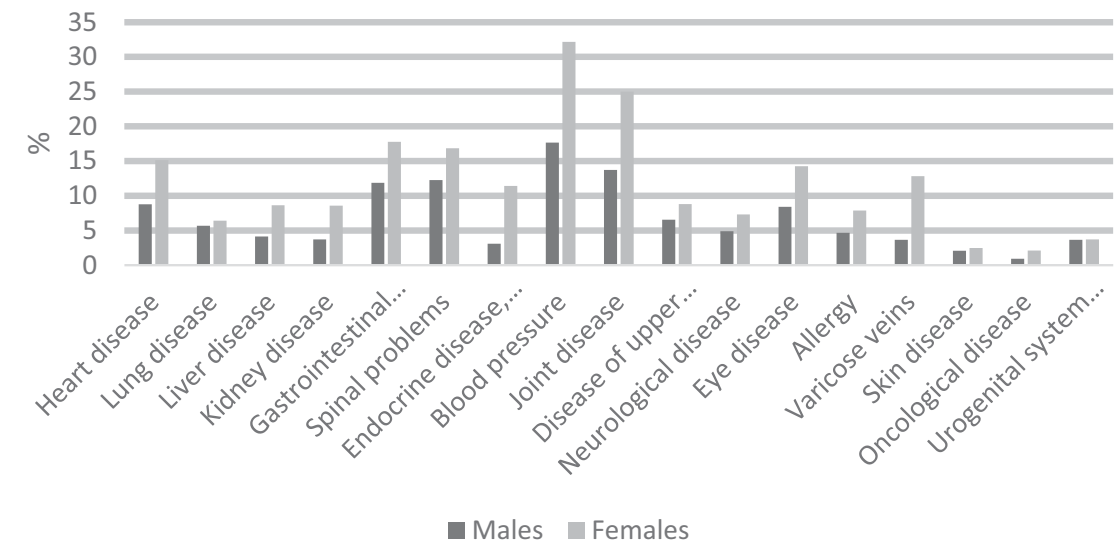

Fig. 1 Prevalence of chronic illness reported in the Russia Longitudinal Monitoring Survey, 2013-2016

are 18 combinations with prevalence of over $50 \%$, an additional 25 with prevalence between 40 and 50\%, a further 62 with prevalence between 25 and $40 \%$ and 167 with less than $25 \%$ prevalence. The strongest dual morbidities involve combinations with high blood pressure and joint disease. For these two conditions alone, all related dual morbidities are at least $35 \%$, and two-thirds of them are greater than $50 \%$. The categories of heart disease, gastrointestinal disease and spinal conditions are also strongly featured among the common combinations we observe. In these data, heart disease exhibits dual morbidity rates of over $40 \%$ with liver disease, diabetes, high blood pressure, oncological disease and urogenital system disease, as well as high multimorbidity rates with kidney, neurological and joint disease. To maximise cell size and produce plausible estimates, in our econometric work, we focus on the 18 dual multimorbidities with prevalence of over $50 \%$.

The independent variables comprise of a typical set of explanatory variables, including gender, age, marital status, education, work status, religious affiliation, individual income quintile, presence of children in the household, household size, regional location and settlement type. These allow us to explore how socioeconomic and demographic characteristics influence self-assessed health outcomes in the presence of chronic NCDs and the related combinations of NCDs. The healthy baseline sample is evenly split in terms of gender. The largest age group is the 14-34 age group (46\%), with 30\% in the 35-49 age bracket and just $3 \%$ aged over 64 . Almost two-thirds of the sample are married, and a similar proportion have children, while the average household size is 3.77 . Concerning education, $25 \%$ of the respondents have a university degree and around one-fifth have incomplete secondary education. Two-thirds of the sample are active in the labour market, while a fifth are formally outside of the labour force, either on maternity (or other) leave or in full-time education. The sample is distributed across the income quintiles, with higher representation among the lowest and highest quintiles. Full variable definitions and descriptive statistics are presented in Appendix Table 4. 
As explained above, we have merged the categories 'bad' and 'very bad', and 'good' and 'very good' to form a dependent variable (SAH) with three categories (good, average and bad) which are ordered so that higher values are associated with progressively less good health conditions. We apply an iterative partial proportional odds model — a special case of the generalized ordered logit model — of the following form:

$$
P\left(Y_{i}>j\right)=g\left(X \beta_{j}\right)=\frac{\exp \left(\alpha_{j}+X_{i} \beta_{j}\right)}{1+\left\{\exp \left(\alpha_{j}+X_{i} \beta_{j}\right)\right\}}, j=1,2, \ldots, M-1
$$

In (1), the probabilities of the dependent variable, $Y$, taking on each of the values $1, . . M$, where $M$ is the number of categories, is equal to:

$$
\begin{gathered}
P\left(Y_{i}=1\right)=1-g\left(X_{i} \beta_{1}\right) \\
P\left(Y_{i}=j\right)=g\left(X_{i} \beta_{j-1}\right)-g\left(X_{i} \beta_{j}\right), j=2, \ldots M-1 \\
P\left(Y_{i}=M\right)=g\left(X_{i} \beta_{M-1}\right)
\end{gathered}
$$

When $M>2$, the model becomes equivalent to a series of binary logistic regressions, in which the categories of the dependent variables are combined (Williams 2006). In this analysis, where $M=3$, for the $J=1$ case, category one (good health) is contrasted with categories two and three (average health and bad health) and for the $J=2$ case, categories one and two (good health and average health) are contrasted with category three (bad health). That is, when there are three categories, the generalized ordered logit model (following an iterative process which ends once all the possible parallel lines assumptions have been tested) produces two sets of odds ratios for each relationship which violates the parallel lines assumption. The first set of estimates represents the impact that a unit change in the independent variable has on the odds ratio of being in 'bad or average health' rather than 'good health' (i.e. not good health), while the second set refers to the corresponding impact on the odds ratio of being in 'bad health' rather than 'average and good health'.

We first estimate a baseline model to ensure that the relationships between the independent socioeconomic and demographic variables and the dependent SAH variable are consistent with the literature, and so that we can observe any important changes in these relationships when we increase the sample size to incorporate those respondents reporting chronic NCDs. We then estimate the baseline regression 13 times, incorporating the 13 most common chronic NCDs associated with the 18 most frequently observed dual NCD morbidities. In estimating these models, we take care to ensure that the anchor category is correctly specified and that we obtain the 'pure' effect of each individual condition. Put differently, we ensure that the comparator group for each chronic condition consists of all the individuals who have not reported having a chronic NCD (i.e. those in full health). This ensures that the reported odds ratios reflect the 'quality of life' impact of having a specific chronic NCD versus having no chronic conditions at all. Following a similar logic, we then estimate the series of 18 common combinations, comparing the impact of having one of a given pair of chronic NCDs, and having both of those NCDs, against a baseline population with no chronic NCDs. Obtaining the 'pure' effects excludes all respondents reporting any other individual NCD or combination of NCDs in a manner that facilitates direct comparison between the effect sizes of different conditions and combined morbidities. Since these 
excluded respondents are more likely to report bad health, the 'cost' of obtaining the pure effects of each NCD and combination of NCDs is that the proportion of individuals in the anchor category who report having bad health is reduced. As robustness checks, we therefore repeat the estimates without these strict exclusion criteria and obtain the gross effects of each condition and combination of conditions.

\section{Results}

Table 1 presents the odds ratios and associated confidence intervals for estimates of the baseline model described above. The results are consistent with the previous literature for Russia (Kaneva 2016; Kaneva et al. 2018) and elsewhere (Cairney 2000; Monden and Uunk 2013), finding strong evidence that males, those with higher education and income levels, those 'on leave' from the labour market, those associating with Islam and those in the major metropolis areas (Moscow and St. Petersburg) are less likely to report average or bad health compared with good health. In contrast, the likelihood of reporting bad or average health increases with age, is higher among married individuals and pensioners (even controlling for age) and increases for the residents of oblast centres and regions outside of Moscow and St. Petersburg. The partial proportional odds model allows us to distinguish an additional set of effects demonstrating that pensioners, the unemployed, respondents in smaller households and those with the lowest level of education are especially likely to report bad health rather than average or good health. ${ }^{5}$

Note that, the baseline regression is estimated on a sub-sample that reports no chronic NCDs because, in contrast to previous literature, we want to explore what the pure effect is of incorporating into the baseline sample those reporting specific NCDs and combinations of NCDs. Table 2 therefore reports the corresponding odds ratios for the 13 chronic NCDs that produce the 18 most common dual morbidities.

As expected, the odds ratios are all considerably greater than one, demonstrating that the likelihood of reporting bad and average health rather than good health for those with individual chronic NCDs is significantly increased compared to the sample of individuals without chronic NCDs. These odds ratio range from 15.46 for cancer to 1.81 for varicose veins and are all strongly statistically significant. Table 2 also indicates that there are six cases in which the proportional odds vary between the two dependent variable classifications and that in each case, the odds for reporting bad (rather than average/good) health are higher than the odds of reporting bad or average (rather than good) health. In these cases (heart, lung, liver, spinal, neurological and cancer), the identification of the pure effect of experiencing one specific chronic NCD provides overwhelming evidence that the most severe NCDs are associated with a very strong likelihood of reporting the lowest level of self-assessed health (e.g. OR for cancer is 82.72).

These reported effects are 'pure' effects in the sense that they capture the impact of conditions experienced by an individual not reporting any other illnesses and interpreted relative to a sample that reports no chronic conditions at all. To identify the impact of the dual morbidities on self-assessed health, we interact each NCD with its partner NCD to

\footnotetext{
${ }^{5}$ Note that, due to the small cell size, the proportional odds model is unable to estimate the second category for the religious denomination variables, and we therefore constrain these to be equal across categories. This has no qualitative impact on our results.
} 
Table 1 Generalized ordered logit model for self-assessed health, baseline regression. Russia Longitudinal Monitoring Survey, 2013-2016

\begin{tabular}{|c|c|c|c|c|}
\hline & \multicolumn{2}{|c|}{ Bad and ave. vs good } & \multicolumn{2}{|c|}{ Bad vs. good and ave. } \\
\hline & OR & $\mathrm{CI}$ & OR & $\mathrm{CI}$ \\
\hline Gender & 0.74 & $(0.68-0.81)$ & & \\
\hline Age 2 & 1.56 & $(1.42-1.72)$ & & \\
\hline Age 3 & 2.95 & $(2.59-3.36)$ & 1.17 & $(0.72-1.91)$ \\
\hline Age 4 & 4.11 & $(3.17-5.33)$ & & \\
\hline Single & 0.77 & $(0.68-0.88)$ & & \\
\hline Divorced & 0.96 & $(0.83-1.11)$ & & \\
\hline Widowed & 0.93 & $(0.76-1.15)$ & & \\
\hline Kids & 1.33 & $(1.18-1.49)$ & & \\
\hline Household size & 0.94 & $(0.91-0.96)$ & 0.79 & $(0.67-0.92)$ \\
\hline Basic education & 0.83 & $(0.55-1.25)$ & 3.37 & $(1.65-6.88)$ \\
\hline Incomplete secondary & 0.95 & $(0.85-1.07)$ & & \\
\hline Technical \& medical & 0.89 & $(0.80-0.98)$ & & \\
\hline University & 0.80 & $(0.72-0.89)$ & & \\
\hline Pensioner & 1.55 & $(1.28-1.88)$ & 5.18 & $(3.18-8.42)$ \\
\hline Out of labour force & 0.70 & $(0.62-0.80)$ & & \\
\hline Unemployed & 1.06 & $(0.93-1.22)$ & 2.66 & $(1.48-4.76)$ \\
\hline Income decile 1 & 1.26 & $(1.10-1.44)$ & & \\
\hline Income decile 2 & 1.31 & $(1.16-1.49)$ & & \\
\hline Income decile 3 & 1.23 & $(1.10-1.38)$ & 0.64 & $(0.36-1.16)$ \\
\hline Income decile 4 & 1.04 & $(0.94-1.15)$ & & \\
\hline Orthodox denomination & 1.11 & $(1.00-1.24)$ & & \\
\hline Islamic denomination & 0.39 & $(0.32-0.49)$ & & \\
\hline Other religion & 0.95 & $(0.65-1.40)$ & & \\
\hline PGT & 0.49 & $(0.41-0.58)$ & 0.98 & $(0.55-1.78)$ \\
\hline Rural & 0.82 & $(0.74-0.91)$ & & \\
\hline Town & 0.78 & $(0.71-0.87)$ & & \\
\hline North and Northwest & 2.07 & $(1.70-2.51)$ & & \\
\hline Central \& Central BE & 2.08 & $(1.78-2.43)$ & & \\
\hline Volga \& Volga-Vyatski & 1.45 & $(1.24-1.69)$ & & \\
\hline North Caucasus & 0.98 & $(0.82-1.18)$ & & \\
\hline Urals & 1.31 & $(1.11-1.54)$ & & \\
\hline Western Siberia & 1.54 & $(1.28-1.85)$ & & \\
\hline Eastern Siberia \& Far East & 1.20 & $(1.01-1.43)$ & & \\
\hline 2014 & 1.01 & $(0.94-1.08)$ & & \\
\hline 2015 & 0.97 & $(0.90-1.04)$ & & \\
\hline 2016 & 0.88 & $(0.82-0.95)$ & & \\
\hline Wald chi-squared (43) & 1977.13 & & & \\
\hline Total observations & 24,798 & & & \\
\hline
\end{tabular}

Only the coefficients that differ to category 1 are listed in the second column 
Table 2 Generalized ordered logit models, regressions for 13 chronic NCDs (baseline + condition), dependent variable SAH, Russia Longitudinal Monitoring Survey, 2013-2016

\begin{tabular}{llllll}
\hline & \multicolumn{2}{l}{ Bad and average vs. good } & & \multicolumn{2}{l}{ Bad vs. good and average } \\
\cline { 2 - 3 } & Odds ratios & CI & & Odds ratios & CI \\
\hline Heart disease & $7.51^{\mathrm{b}}$ & $(5.77-9.78)$ & & 18.87 & $(12.43-26.66)$ \\
Lung disease & 5.28 & $(4.26-6.54)$ & & 11.73 & $(7.84-17.56)$ \\
Liver disease & 4.46 & $(3.37-5.90)$ & & 9.08 & $(5.21-15.82)$ \\
Kidney disease & 3.34 & $(2.66-4.20)$ & & \\
Gastro disease & 3.46 & $(2.95-3.80)$ & & $(4.60-10.56)$ \\
Spinal disease & 3.45 & $(2.96-4.02)$ & & 6.97 & \\
Endocrine/diabetes & 5.46 & $(4.07-7.30)$ & & \\
High blood pressure & 3.57 & $(3.10-4.10)$ & & \\
Joint disease & 3.70 & $(3.00-4.55)$ & & \\
Neurological disease & 6.76 & $(4.92-9.29)$ & 24.43 & \\
Eye disease & 2.56 & $(1.90-2.67)$ & & \\
Varicose veins & 1.81 & $(1.43-2.29)$ & & \\
Cancer & 15.46 & $(5.30-45.10)$ & 82.72 & \\
Urogenitary disease & 3.28 & $(5.09-2.16)$ & & \\
\hline
\end{tabular}

a Same regressors as in baseline regressions (Table 1)

Only the coefficients that differ to category 1 are listed in the second column

obtain the interaction effects reported in Table 3. The contribution of the partner condition, to the self-assessment, can then be isolated by multiplying the main effect of that condition by the interaction effect. If the interaction effect is greater than one, the combined effect of the NCDs is more than the sum of the individual NCDs (what we call, 'synergy'); while, if the interaction effect is less than one, the combined effect of the NCDs is below the sum of the individual NCDs (what we call, 'adaptation').

While Table 2 clearly shows that each chronic NCD significantly and negatively impacts on self-assessed health, Table 3 shows that, where there are dual morbidities, there is no evidence in support of a synergistic effect. Specifically, in nearly all cases, the interaction term is well below one, is statistically significant and covers a relatively narrow range between 0.20 (cancer interacted with blood pressure) and 0.58 (diabetes interacted with blood pressure). In the former case, this suggests that the impact of high blood pressure on the likelihood of reporting bad/average health (rather than good health), given the individual has self-reported cancer, is about one-fifth what the effect would have been $(\mathrm{OR}=3.57)$ had the individual been in otherwise full health. In the case of diabetes and blood pressure, the impact of the second disease, in the presence of the first, is around half what it would have been had the first not existed. Put differently, in nearly all cases, the effect of one of the diseases of interest on self-assessed health is much weaker in the presence of another disease than it would be if experienced alone as a single chronic NCD. ${ }^{6}$

\footnotetext{
${ }^{6}$ The proportional odds model is unable to produce estimates for the interaction of urogenitary disease and blood pressure, and we therefore constrain these to be equal across categories. This has no qualitative impact on our results.
} 
Table 3 Generalized ordered logit models, regressions with interactions for 18 most common comorbidities regressions for 13 chronic NCDs (baseline + condition), dependent variable SAH, Russia Longitudinal Monitoring Survey, 2013-2016

\begin{tabular}{|c|c|c|c|c|}
\hline & \multicolumn{2}{|c|}{ Bad and average vs. good } & \multicolumn{2}{|c|}{ Bad vs. good and average } \\
\hline & Odds ratios & CI & Odds ratios & CI \\
\hline Heart $\times$ pressure & 0.34 & $(0.24-0.49)$ & & \\
\hline Liver $\times$ pressure & 0.45 & $(0.23-0.88)$ & & \\
\hline Kidney $\times$ pressure & 0.41 & $(0.21-0.81)$ & & \\
\hline Spine $\times$ pressure & 0.42 & $(0.28-0.63)$ & & \\
\hline Diabetes $\times$ pressure & 0.58 & $(0.36-0.92)$ & & \\
\hline Joint $\times$ pressure & 0.38 & $(0.28-0.53)$ & & \\
\hline Neurological $\times$ pressure & 0.51 & $(0.28-0.90)$ & & \\
\hline Eye $\times$ pressure & 0.43 & $(0.29-0.65)$ & & \\
\hline Varicose veins $\times$ pressure & 0.68 & $(0.39-1.19)$ & & \\
\hline Cancer $\times$ pressure & 0.20 & $(0.06-0.62)$ & & \\
\hline Urogenitary $\times$ pressure & 1.06 & $(0.49-2.31)$ & & \\
\hline Liver $\times$ gastro & 0.51 & $(0.31-0.86)$ & & \\
\hline Heart $\times$ joint & 0.79 & $(0.24-2.56)$ & 0.20 & $(0.10-0.43)$ \\
\hline Liver $\times$ joint & 0.51 & $(0.31-0.86)$ & & \\
\hline Spinal $\times$ joint & 0.46 & $(0.32-0.66)$ & & \\
\hline Neurological $\times$ joint & 0.26 & $(0.12-0.56)$ & & \\
\hline Varicose Veins $\times$ joint & 0.48 & $(0.29-0.81)$ & & \\
\hline Urogenitary $\times$ joint & 0.42 & $(0.11-1.52)$ & & \\
\hline
\end{tabular}

${ }^{a}$ Individual effect assumed to be as per the regressions in Table 2 above; only interactions reported Only the coefficients that differ to category 1 are listed in the second column

Finally, these results are robust to different specifications and different approaches to identify the anchor condition as well as returning plausible results concerning the relationship between self-assessed health and socioeconomic and demographic indicators, which are consistent across specifications and sub-samples and are robust to different combinations of independent variables being used within the empirical framework. In results excluded from this paper due to space constraints, we estimate the impact of an individual reporting a new chronic condition, controlling for existing conditions and then examining an interaction effect of the new NCD and the existing number of NCDs. We find that a new NCD is bad for self-assessed health, having more NCDs is also bad for self-assessed health but—in an echo of our main results - the interaction effects produce odds ratios of less than one. That is, the new NCD has a lower incremental impact on SAH than it would have done in the absence of other NCDs.

\section{Discussion}

This paper explored the relationship between 17 chronic NCDs, their associated multimorbidities and self-assessed health in Russia. The prevalence of chronic NCDs 
and combinations of more than one NCD is high in Russia. Almost one-third of women and one-fifth of men report having high blood pressure; prevalence rates for joint disease, gastrointestinal disease, spinal problems and heart disease, range between 15 and $25 \%$ for women, and 9 and $14 \%$ for men; and there are 18 dual combinations of chronic NCDs with prevalence higher than $50 \%$.

The pure effects (on the likelihood of not reporting good health) of each individual NCD are strongly statistically significant, with odds ratios considerably greater than one, ranging from 15.46 for cancer to 1.81 for varicose veins. In comparison with the odds ratios reported by Kaneva et al. (2018), these reported ratios are an order of magnitude higher, and unlike in that paper, we find significant effects for seemingly less severe NCDs such as allergies, eye disease and varicose veins. This is because we are specifically identifying the pure effect of having exactly one NCD relative to a sample baseline with no other NCDs. This represents an important difference between our approach and that typical in the literature. It allows us to see, for example, that in comparison with a (healthy) baseline group with no chronic NCDs, having varicose veins does have real negative effects on health satisfaction.

Turning to multimorbidity, we find that the odds ratios for the interaction effects between common morbidities are significant and less than one, indicating that the total effect of any two NCDs is smaller than would be the case, were we to simply aggregate the two corresponding individual effects. To illustrate, the independent pure effects (in odds ratios) of heart disease and high blood pressure are respectively 7.51 and 3.57 , while the interaction effect is 0.34 . Ignoring the interaction effect implies an odds ratio of 26.8 for this combination of conditions, while factoring in the interaction effect, produces an alternative and much reduced odds ratio of 9.12 .

This is a significant finding, reflecting that, when an individual suffers from a chronic condition, there is both a direct (physical) and an indirect (psychological) effect of the illness. The indirect effect includes factors relating to lifestyle changes, the costs of adhering to complex treatment regimens, the diminished ability to participate in activities and the ongoing anxiety regarding the prognosis. These results (Table 3) reflect that, even if the direct (physical) effects are synergistic, individuals are better equipped (psychologically) for adapting to the indirect psychological costs of a second illness. Moreover, this adaptation effect is bigger the more severe one of the NCDs is. In other words, individuals make significant adaptations as they accumulate additional NCDs - a process, which most plausibly stems from the indirect, psychological effects of illness, rather than the direct physical effects.

This is the central finding of our paper, and it is important for at least three reasons. First, it provides empirical evidence consistent with theories of indirect psychological, physical and lifestyle adaptation to major life transitions. The results demonstrate that an accumulation of NCDs gives rise to processes that reflect the idea of adaptation as 'an intrapsychic process in which past, present, and future situations and circumstances are given such cognitive and emotional meaning that an acceptable level of well-being is achieved' (Heynik 1993). Second, adaptation is also consistent with economic models of health (Grossman 1972) which are predicated on a non-linear health production function. Adaptation should therefore be factored into the management of multimorbidity, the measurement of quality of life and the allocation of scarce resources, in addition to incorporation within complex disease management and other clinical protocol (Hausman 2008). Third, the global advance of multimorbidity opens 
up new demands for healthcare intervention. Indeed, as we grow to understand the qualitative impact that multimorbidity has on individual lives, the complex implications for policy making and resource allocation will also merit greater consideration.

The study is not without limitations. First, this is a population study and not a patient study. While it is not inconceivable that a hospital study of patients would identify different processes of adaptation, our concern is specifically with the adaptation of the population to common illnesses they encounter. Second, in identifying the pure effect of chronic NCDs, we necessarily sacrifice sample size, but we argue that this is a necessary trade-off in order to identify the actual effects on self-assessed health of specific diseases. Third, there are those that caution against self-assessed measures of health. However, not only has previous research shown that it is a good predictor of both morbidity and mortality (Mossey and Shapiro 1982; Kaplan and Camacho 1983) but there is a strong argument, beyond this, that how individuals feel about their health is important regardless of clinical diagnosis. Indeed, this argument lies at the heart of Health Technology Assessment techniques (WHO 2015).

\section{Conclusion}

With ageing populations, higher life expectancies and growing technological opportunities, multiple chronic illness is becoming one of the foremost health system challenges of the twenty-first century. Aside from growing and complex demands on healthcare systems, growing numbers of people will be faced with the task of adapting to life with multiple chronic NCDs. In this context, understanding how and whether processes of adaptation impact on individual health-related quality of life becomes a critical issue for policy makers, health economists and healthcare managers. This has particular importance for Russia where, in 2014, legislative reforms (Law No. 429-FZ) were introduced which formally embraced Health Technology Assessment and resulted in the Ministry of Health establishing a 'Center for Healthcare Quality Assessment and Control'. This now serves as the main official agency in Russia charged with delivering improved processes, guidelines, transparency and public education in the field of healthcare decision making (Khabibullina and Gerry 2019).

In conclusion, we have provided the first estimates capturing adaptation to disease using individual level data from Russia. We have documented high levels of chronic NCDs and combinations of chronic NCDs; we have identified the pure effect of these conditions and a subset of their associated multimorbidities on self-reported health, and through exploring interaction effects, have presented compelling evidence that individuals do adapt in the face of accumulating chronic NCDs. If this is the case then, through its impact on quality of life, adaptation has implications for healthcare resource management, clinical practice and the way in which health economics is used in public health. Understanding how combinations of disease impact upon individuals and how positive experiences of adaptation - within and across diseases - can be promoted, is a multidisciplinary and multisectorial challenge, spanning the disciplines of the natural and social sciences and calling on stakeholders from the public and private sectors.

Acknowledgements We are grateful to participants in RANEPA, HSE and University of Oxford seminars for helpful comments on this paper. The study was carried out within a framework of the Russian Foundation 
for Basic Research (RFBR), project number 20-010-00205 'The role of health capital in the socio-economic development of Russian regions'.

Funding Information This work was supported by the Russian Presidential Academy of National Economy and Public Administration, Moscow (RANEPA). The reported study was funded by RFBR, project number 20-010-00205.

\section{Compliance with Ethical Standards}

Conflict of Interest The authors declare that they have no conflict of interest.

\section{Appendix}

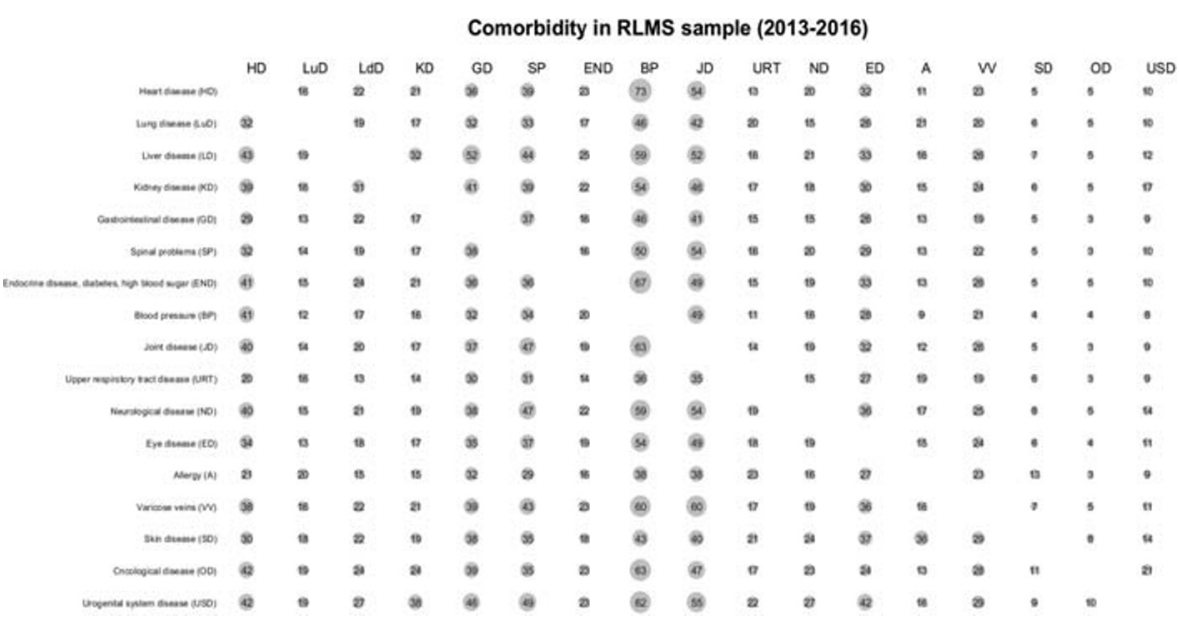

Fig. 2 Comorbidity in the RLMS, 2013-2016. Percentage of patients with the row NCD who also have the column NCD. To illustrate, $73 \%(54 \%)$ of those reporting heart disease (row 1) report high blood pressure (joint disease). 
Table 4 Descriptive statistics (healthy baseline sample; $N=24,798$ )

\begin{tabular}{|c|c|c|}
\hline Variable name & Definition & Mean (SD) \\
\hline $\mathrm{SAH}$ & Self-assessed health $(1=$ good health; $2=$ average health; $3=$ bad health $)$ & $1.33(0.48)$ \\
\hline Gender & $0=$ female; $1=$ male & $0.51(0.50)$ \\
\hline Age $1 *$ & $\begin{array}{l}\text { Age group } 1 \\
1=\text { individuals below } 34 ; 0=\text { otherwise }\end{array}$ & $0.46(0.50)$ \\
\hline Age 2 & $\begin{array}{l}\text { Age group } 2 \\
1=\text { individuals are aged } 35-49 ; 0=\text { otherwise }\end{array}$ & $0.30(0.46)$ \\
\hline Age 3 & $\begin{array}{l}\text { Age group } 3 \\
1=\text { individuals are aged } 50-64 ; 0=\text { otherwise }\end{array}$ & $0.13(0.33)$ \\
\hline Age 4 & $\begin{array}{l}\text { Age group } 4 \\
1=\text { if individuals are } 65-102 ; 0=\text { otherwise }\end{array}$ & $0.03(0.17)$ \\
\hline Sing & $1=$ single $; 0=$ otherwise & $0.27(0.44)$ \\
\hline Div & $1=$ divorced or married but not living together; $0=$ otherwise & $0.06(0.25)$ \\
\hline Wid & $1=$ widowed; $0=$ otherwise & $0.03(0.17)$ \\
\hline Mard* & $1=$ married; $0=$ otherwise & $0.64(0.48)$ \\
\hline Kids & $1=$ has children; $0=$ otherwise & $0.64(0.48)$ \\
\hline HH size & Number of people in household (1-16) & $3.78(1.75)$ \\
\hline Basic & $1=$ basic education, 6 grades or fewer; $0=$ otherwise & $0.01(0.09)$ \\
\hline Inscec & $1=$ incomplete secondary education; $0=$ otherwise & $0.20(0.40)$ \\
\hline Second* & $1=$ secondary education; $0=$ otherwise & $0.32(0.47)$ \\
\hline Tecmed & $\begin{array}{l}1=\text { technical and medical education below university education; } 0= \\
\text { otherwise }\end{array}$ & $0.22(0.42)$ \\
\hline Uni & $1=$ higher education or graduate degree; $0=$ otherwise & $0.25(0.44)$ \\
\hline Work* & $1=$ employed; $0=$ otherwise & $0.63(0.48)$ \\
\hline Pens & $1=$ retired $0=$ otherwise & $0.06(0.23)$ \\
\hline Out_lf & $1=$ out of labour force; $0=$ otherwise & $0.21(0.41)$ \\
\hline Unemp & $1=$ unemployed; $0=$ otherwise & $0.10(0.30)$ \\
\hline perc5_inc_dum1 & $1=$ first income quintile $; 0=$ otherwise & $0.27(0.45)$ \\
\hline perc5_inc_dum2 & $1=$ second income quintile $; 0=$ otherwise & $0.14(0.35)$ \\
\hline perc5_inc_dum3 & $1=$ third income quintile $; 0=$ otherwise & $0.15(0.36)$ \\
\hline perc5_inc_dum4 & $1=$ forth income quintile; $0=$ otherwise & $0.24(0.43)$ \\
\hline perc5_inc_dum5* & $1=$ fifth income quintile; $0=$ otherwise & $0.20(0.40)$ \\
\hline Orthod & $1=$ religion is Orthodoxy $; 0=$ otherwise & $0.80(0.41)$ \\
\hline Isl & $1=$ religion is Islam; $0=$ otherwise & $0.09(0.28)$ \\
\hline Reloth & $1=$ another religion (not Islam or Orthodoxy); $0=$ otherwise & $0.01(0.08)$ \\
\hline Athe* & $1=$ atheism $0=$ otherwise & $0.11(0.31)$ \\
\hline Ob_centr* & $1=$ regional (oblast) centre $0=$ otherwise & $0.38(0.48)$ \\
\hline Pgt & $1=$ urban-type settlement; $0=$ otherwise & $0.08(0.27)$ \\
\hline Rural & $1=$ rural settlement $0=$ otherwise & $0.28(0.45)$ \\
\hline Town & $1=$ town $0=$ otherwise & $0.27(0.44)$ \\
\hline North & $1=$ resident in North or Northwest; $0=$ otherwise & $0.06(0.24)$ \\
\hline Centr & $1=$ resident in Central $/$ Central Black Earth; $0=$ otherwise & $0.19(0.39)$ \\
\hline Volga & $1=$ resident in Volga or Volga-Vyatski; $0=$ otherwise & $0.18(0.38)$ \\
\hline
\end{tabular}


Table 4 (continued)

\begin{tabular}{|c|c|c|c|}
\hline Variable name & \multicolumn{2}{|l|}{ Definition } & Mean (SD) \\
\hline Cauca & \multicolumn{2}{|l|}{$1=$ resident in North Caucasus; $0=$ otherwise } & $0.16(0.37)$ \\
\hline Ural & \multicolumn{2}{|l|}{$1=$ resident in Urals; $0=$ otherwise } & $0.15(0.35)$ \\
\hline West & \multicolumn{2}{|l|}{$1=$ resident in West Siberia; $0=$ otherwise } & $0.08(0.27)$ \\
\hline East & \multicolumn{2}{|c|}{$1=$ resident in East Siberia or Far East; $0=$ otherwise } & $0.09(0.29)$ \\
\hline Capit* & \multicolumn{2}{|c|}{$1=$ resident in Moscow or St. Petersburg; $0=$ otherwise } & $0.09(0.14)$ \\
\hline \multicolumn{4}{|c|}{ Additional descriptive statistics for samples incorporating respondents with chronic NCDs } \\
\hline Heart & $1=$ heart disease $; 0=$ otherwise & $(N=25,283)$ & $0.02(0.14)$ \\
\hline Joint & $1=$ joint disease $; 0=$ otherwise & $(N=25,561)$ & $0.03(0.17)$ \\
\hline Hypertension & $1=$ hypertension $; 0=$ otherwise & $(N=26,446)$ & $0.06(0.24)$ \\
\hline Gastrointestinal & $1=$ gastrointestinal disease $; 0=$ otherwise & $(N=26,548)$ & $0.07(0.25)$ \\
\hline Spine & $1=$ spine problems $; 0=$ otherwise & $(N=25,932)$ & $0.04(0.21)$ \\
\hline Liver & $1=$ liver disease; $0=$ otherwis & $(N=25,170)$ & $0.02(0.12)$ \\
\hline Lung & $1=$ lung disease $; 0=$ otherwise & $(N=25,486)$ & $0.03(0.16)$ \\
\hline Kidney & $1=$ kidney disease $; 0=$ otherwise & $(N=23,339)$ & $0.02(0.14)$ \\
\hline Neurological & $1=$ neurological disease $; 0=$ otherwise & $(N=25,174)$ & $0.02(0.12)$ \\
\hline Diabetes & $1=$ diabetes; $0=$ otherwise & $(N=25,200)$ & $0.02(0.13)$ \\
\hline Cancer & $1=$ cancer $; 0=$ otherwise & $(N=24,889)$ & $0.004(0.06)$ \\
\hline Eye & $1=$ eye disease $; 0=$ otherwise & $(N=25,822)$ & $0.04 \mathrm{~m}(0.20)$ \\
\hline Vein & $1=$ varicose veins $; 0=$ otherwise & $(N=25,178)$ & $0.02(0.12)$ \\
\hline
\end{tabular}

*Denotes reference category in the regression estimates

Open Access This article is licensed under a Creative Commons Attribution 4.0 International License, which permits use, sharing, adaptation, distribution and reproduction in any medium or format, as long as you give appropriate credit to the original author(s) and the source, provide a link to the Creative Commons licence, and indicate if changes were made. The images or other third party material in this article are included in the article's Creative Commons licence, unless indicated otherwise in a credit line to the material. If material is not included in the article's Creative Commons licence and your intended use is not permitted by statutory regulation or exceeds the permitted use, you will need to obtain permission directly from the copyright holder. To view a copy of this licence, visit http://creativecommons.org/licenses/by/4.0/.

\section{References}

Ambrosio, L., et al. (2015). Living with chronic illness in adults: a concept analysis. Journal of Clinical Nursing, 24, 2357-2367.

Antonak, R., \& Livneh, H. (1995). Psychological adaptation to disability and its investigation among people with multiple sclerosis. Social Science and Medicine, 40(8), 1099-1108.

Arokiasamy, P., Uttamacharya, U., Jain, K., et al. (2015). The impact of multimorbidity on adult physical and mental health in low- and middle-income countries: what does the study on global ageing and adult health (SAGE) reveal? BMC Medicine, 13, 178.

Brickman, P., \& Coates, D. (1978). Lottery winners and accident victim: is happiness relative? Journal of Personality and Social Psychology, 36(8), 917-927.

Cairney, J. (2000). Socio-economic status and self-rated health among older Canadians. Canadian Journal of Aging, 19(4), 456-478. 
Cohen, F., \& Lazarus, R. S. (1979). Coping with the stress of illness. In C. G. Stone, F. Cohen, \& N. E. Adler (Eds.), Health psychology: a handbook (pp. 217-254). San Francisco: Jossey-Bass.

Corr, C. A., Nabe, C. M., \& Corr, D. M. (2003). Death and dying, life and living. Belmont: Wadsworth.

Cubí-Mollá, P., Jofre-Bonet, M., \& Serra-Sastre, V. (2017). Adaptation to health states: sick yet better off? Health Economics, 26(12), 1826-1843.

Fortin, M., Lapointe, L., Hudon, C., Vanasse, A., Ntetu, A., \& Maltais, D. (2004). Multimorbidity and quality of life in primary care: a systematic review. Health and Quality of Life Outcomes, 2, 51.

Garin, N., Koyanagi, A., Chatterji, S., Tyrovolas, S., Olaya, B., et al. (2016). Global multimorbidity patterns: a cross-sectional, population-based, multi-country study. Journal of Gerontology, 71(2), 205-214.

Grossman, M. (1972). On the concept of health capital and the demand for health. Journal of Political Economy, 2, 223-255.

Guthrie, B., Wyke, S., Gunn, J., van den Akker, J., \& Mercer, S.W. (2011). Multimorbidity: the impact on health systems and their development. In: Health reform: meeting the challenge of ageing and multiple morbidities. Paris: OECD Publishing. https://doi.org/10.1787/9789264122314-9-en

Hausman, D. (2008). Valuing health properly. Health Economics, Policy, and Law, 3(1), 79-83.

Heynik, J. (1993). Adaptation and well-being. Psychological Reports, 73, 1331-1342.

Howard, D., Thorpe, K., \& Busch, S. (2010). Understanding recent increases in chronic disease treatment rates: more disease or more detection? Health Economics, Policy, and Law, 5(4), 411-435.

Kaneva, M. A. (2016). Sotsial'no-ehkonomicheskie, povedencheskie i psikhologicheskie determinanty zdorov'ya rossiyan [socio-economic, behavioral and psychological determinants of the health status of the Russians]. Natsional'nye Interesy: Prioritety i Bezopasnost' [National Interests: Priorities and Security], 1, 158-171 (in Russian).

Kaneva, M., Gerry, C., \& Baidin, V. (2018). The effect of chronic conditions and self-assessed health in Russia. Scandinavian Journal of Public Health, 46, 886-896.

Kaplan, G. A., \& Camacho, T. (1983). Perceived health and mortality: a nine-year follow-up of the human population laboratory cohort. American Journal of Epidemiology, 117(3), 292-304.

Khabibullina, A., \& Gerry, C. J. (2019). Valuing health states in Russia: a first feasibility study. Value in Health Regional Issues, 19, 75-80.

Kübler-Ross, E., \& Kessler, D. (2014). On grief \& grieving: finding the meaning of grief through the five stages of loss. New York: Scribner.

Livneh, H., \& Antonak, R. (2005). Psychosocial adaptation to chronic illness and disability: a primer for counselors. Journal of Counseling and Development, 83, 12-20.

Lorig, K., Holman, H., Sobel, D., Gonzalez, Z., \& Minor, M. (2006). Living a healthy life with chronic conditions. Boulder Colorado: Bull Publishing.

Marengoni, A., Angleman, S., Melis, R., Mangialasche, F., Karp, A., Garmen, A., Meinow, B., \& Fratiglioni, L. (2011). Aging with multimorbidity: a systematic review of the literature. Ageing Research Reviews, 10, 430-439.

Mathew, R., Gucciardi, E., De Melo, M., \& Barata, P. (2012). Self-management experiences and men and women with type 2 diabetes mellitus. BMC Family Practice, 13, 22.

Mavaddat, N., Valderas, J. M., van der Linde, R., Khaw, K. T., \& Kinmonth, A. L. (2014). Association of selfrated health with multimorbidity, chronic disease and psychological factors in a large middle-aged and older cohort from general practice: a cross sectional study. BMC Family Practice, 15, 185.

McDaid, O., Hanley, M. J., Richardson, K., Kee, F., Kenny, R. A., \& Savva, G. M. (2013). The effect of multiple chronic conditions on self-rated health, disability and quality of life among the older population of Northern Ireland and the Republic of Ireland: a comparison of two nationally representative crosssectional surveys. BMJ Open. https://doi.org/10.1136/bmjopen-2013-002571.

McNamee, P., \& Mendolia, S. (2014). The effect of chronic pain on life satisfaction: evidence from Australian data. Social Science and Medicine, 121, 65-73.

McTaggard-Cowan, H., Tsuchiya, A., O’Cathain, A., \& Brazier, J. (2011). Understanding the effect of disease adaptation information on general population for hypothetical health states. Social Science and Medicine, 72, 1904-1912.

Momtaz, Y. A., Hamid, T. A., Yahaya, N., et al. (2010). Effects of chronic comorbidty on psychological wellbeing among older persons in Northern Peninsular Malaysia. Applied Research in Quality of Life, 5(2), $133-146$.

Monden, C. W. S., \& Uunk, W. J. G. (2013). For better and for worse: the relationship between union dissolution and self-assessed health in European panel data. European Journal of Population, 29, 103125 .

Mossey, J. M., \& Shapiro, E. (1982). Self-rated health: a predictor of mortality among the elderly. American Journal of Public Health, 72(8), 800-808. 
Moss-Morris, R. (2013). Adjusting to chronic illness: time for a unified theory. British Journal of Health Psychology, 18, 681-686.

Ording, A. G., \& Sorensen, H. T. (2013). Concept of multiple comorbidities, morbidities, complications, and their clinical epidemiologic analogs. Clinical Epidemiology, 5, 199-203.

Oswald, A., \& Powdthavee, N. (2008). Does happiness adapt? A longitudinal study of disability with implications for economists and judges. Journal of Public Economics, 92, 1061-1077.

Parekh, A. K., \& Barton, M. B. (2010). The challenge of multiple comorbidity for the US health care system. JAMA, 303, 1303-1304.

Salas, G., \& Vigorito, A. (2019). Subjective well-being and adaptation. The case of Uruguay. Applied Research in Quality of Life, 14(3), 685-703.

Samson, A., \& Siam, H. (2008). Adapting to major chronic illness: a proposal for a comprehensive task-model approach. Patient Education and Counseling, 70, 426-429.

Starfield, B. (2006). Threads and yarns: weaving the tapestry of comorbidity. Annals of Family Medicine, 4, 101-103.

Telford, K., Kralik, D., \& Koch, T. (2006). Acceptance and denial: implications for people adapting to chronic illness: literature review. Journal of Advanced Nursing, 55(4), 457-464.

United Nations, General Assembly. (2011). Prevention and control of non-communicable diseases. Resource document. NY: United Nations. http://www.un.org/ga/search/view_doc.asp?symbol=A/66/83\&Lang=E. Accessed 26 August 2018.

WHO. (2015). Global survey on health technology assessment by national authorities. Main findings Geneva: World Health Organization.

Williams, R. (2006). Generalized ordered logit/partial proportional odds models for ordinal dependent variable. Stata Journal, 6, 58-82.

Publisher's Note Springer Nature remains neutral with regard to jurisdictional claims in published maps and institutional affiliations.

\section{Affiliations}

\section{Christopher J Gerry ${ }^{1,2} \cdot$ Maria Kaneva ${ }^{3,4}$}

1 Oxford School of Global and Area Studies (OSGA), University of Oxford, 12 Bevington Road, Oxford OX2 6LH, UK

2 International Centre for Health Economics, Management, and Policy, National Research University Higher School of Economics, St. Petersburg, Russia

3 International Laboratory for Economics of Healthcare and Its Reforms, Gaidar Institute for Economic Policy, Moscow, Russia

4 Institute of Economics and Industrial Engineering, Siberian Branch of the Russian Academy of Sciences, Novosibirsk, Russia 